Hituzi Linguistics in English No.5

Communicating Skills of Intention

Edited by Tsutomu Sakamoto

Hituzi Syobo Publishing

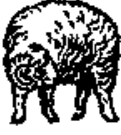




\section{The Memory, Unification, and Control (MUC) Model of Language}

Peter Hagoort

\section{The MUC framework}

Models of language processing distinguish between retrieval of information from long term memory (the mental lexicon) and operations that combine lexical information into larger structures. Memory retrieval and combinatorial operations occur at the levels of meaning, syntax, and phonology. These combinatorial operations result in the unification of the conceptual, syntactic and phonological building blocks that are retrieved from memory. While left temporal cortex plays an important role in lexical retrieval, Broca's area and adjacent cortex seem to be relevant for unification.

The MUC (Memory, Unification, and Control) model provides a framework for a neurobiologically plausible account of language processing. It connects psycholinguistically motivated processing components to their neuronal substrate, guided by knowledge about brain function across domains of cognition. The model distinguishes three functional components of language processing. The Memory component comprises a specification of the different types of language information stored in long term memory, and of their retrieval operations. The Unification component refers to the integration of lexically retrieved information into a representation of multi-word utterances. The Control component relates language to 
action.

According to the MUC model, the left temporal cortex plays a critical role in storage and retrieval of linguistic information that language acquisition has laid down in memory. This refers to the phonological/phonetic properties of words, their syntactic features such as grammatical gender, word class (verb, noun, etc.) including the syntactic frames, and finally the conceptual specifications of the 60.000 or so words that a native speaker of a language such as English has stored in memory. Activations related to phonological/phonetic properties are reported for the central to posterior superior temporal gyrus (STG) extending into the superior temporal sulcus (STS) (Indefrey \& Cutler, 2004; Scott and Johnsrude, 2003; Aleman et al., 2005).

Semantic information is presumably distributed over a number of brain areas, but most likely different parts of the left middle and inferior temporal gyri may be crucially involved in lexical-semantic processing (Damasio et al., 1996; Indefrey and Cutler, 2004; Indefrey and Levelt, 2000; Saffran and Sholl, 1999).

Hardly anything is known about the brain areas involved in the lexical retrieval of a word's syntactic specifications. On the basis of the meta-analysis of a large series of imaging studies on syntactic processing, the hypothesis is that the left posterior superior temporal cortex (Wernicke's area) is involved in the retrieval of lexical-syntactic information.

The Memory component thus seems to be distributed mainly over left temporal cortex. The Control component of the model accounts for the fact that the language system operates in the context of communicative goals and actions. For example, attentional control allows individuals to speak while seeing irrelevant objects or hearing interlocutors, to take turns in conversational settings, or in case of bilingualism to select the correct language in a particular communicative setting. The issue of verbal control has so far only been studied in the context of a Stroop task (Botvinick et al., 2004; Bush et al., 2000; MacLeod \& MacDonald, 2000; Roelofs and Hagoort, 2002). These studies suggest that a network of areas consisting of the anterior cingulate cortex $(\mathrm{ACC})$ and the dosolateral prefrontal cortex (DLPC, BA 46/9) is involved in verbal action planning and attentional control.

Figure 1 summarizes the network of areas subserving the three central compo- 
nents (Memory, Unification, Control) of human language in action. The precise effective connectivity between these areas is a topic for further research.

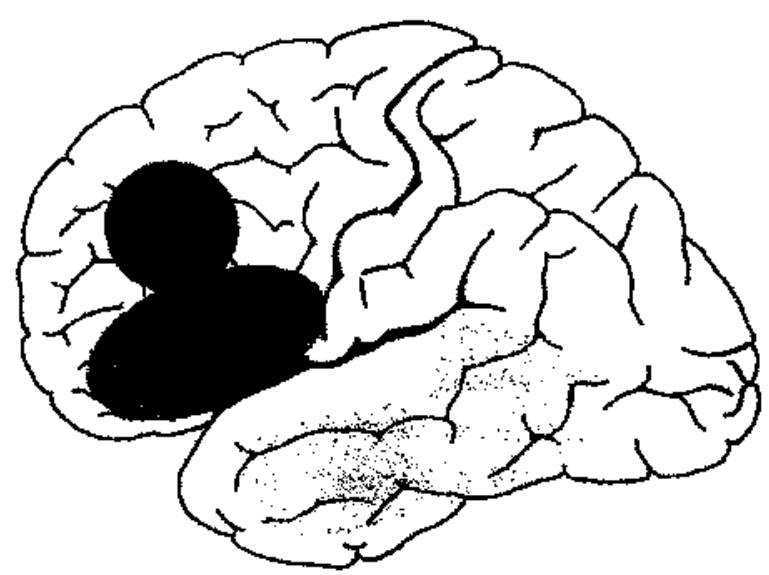

Figure 1. The tbree components of the MUC model projected mito a lateral surjate of the left bemisphere: Memory (light grey) in left temporal cortex, Unification (grey) in Broca's complex, and Control (dark grey) in dorsolateral prefrontal cortex. Tbe $A C C$ (pant of tbe Control component) is not shown.

Hereafter I will mainly focus on the processing principles behind unification. First, I will discuss syntactic unification. Followed by a discussion about semantic unification. In addition, the neural architecture of unification will be discussed.

\section{Syntactic unification}

Recent accounts of the human language system (Jackendoff, 1999; 2002; Leveit, 1999) assume a cognitive architecture, which consists of separate processing levels for conceptual/semantic information, orthographic/phonological information, and syntactic information. Based on this architecture, most current models of language processing agree that, in on-line sentence processing, different types of constraints are very quickly taken into consideration during speaking and listening/reading. Constraints on how words can be structurally combined operate alongside qualitatively distinct constraints on the combination of word meanings, on the grouping 
of words into phonological phrases, and on their referential binding into a discourse model.

Moreover, in recent linguistic theories, the distinction between lexical items and traditional rules of grammar is vanishing. For instance, Jackendoff (2002) proposes that the only remaining rale of grammar is UNIFY PIECES, "and all the pieces are stored in a common format that permits unification." (p. 180). The unification operation clips together lexicalized patterns with one or more variables in it. The operation MERGE in Chomsky's Minimalist Program (Chomsky, 1995) has a similar flavour. Thus, phonological, syntactic, and semantic/pragmatic constraints determine how lexically available structures are glued together.

In models of language processing, there exists a fairly wide agreement on the types of constraints that are effective during the formulation and the interpretation of sentences and beyond. However, disagreement prevails with respect to exactly how these are implemented in the overall sentence processing architecture. One of the key issues is when and how the assignment of a syntactic structure to an incoming string of words and the semantic integration of single word meanings interact during listening/reading. The by now classical view is that in sentence comprehension, the syntactic analysis is autonomous and initially not influenced by semantic variables (Frazier, 1987). Semantic integration can be influenced by syntactic analysis, but it does not contribute to the computation of syntactic structure. An alternative view maintains that lexical-sernantic and discourse information can guide or contribute to the syntactic analysis of the utterance. This view is mainly supported by studies showing that the reading of syntactically ambiguous sentences is immediately influenced by lexical or more global semantic information (e.g., Altmann and Steedman, 1988; Trueswell et al., 1993; 1994; Tyler and Marslen-Wilson, 1977).

Some of the discrepancies between the different views on this topic are due to the fact that no clear distinction is made between cases where the syntactic constraints are, at least temporarily, indeterminate with respect to the structural assignment (syntactic ambiguity), and cases where these constraints are sufficient to determine the syntactic analysis. In the former case, there is a substantial body of evidence for an immediate influence of non-syntactic context information on the structure that is assigned (Tanenhaus and Trueswell, 1995; Van Berkum et al., 
1999a). However, for the latter case, although it has not been studied as intensely, the available evidence seems to provide support for a certain level of syntactic autonomy (Hagoort, 2003; O'Seaghdha, 1997).

A more recent version of the autonomous syntax view is proposed by Friederici (2002). Based on the time course of different language-releyant ERP effects, she proposes a three-phase model of sentence comprehension. The first phase is purely syntactic in nature. An initial syntactic structure is formed on the basis of information about the word category (noun, verb, etc.). During phase two, lexical-semantic and morphosyntactic processes take place, which result in thematic role assignments. In the third phase, integration of the different types of information takes place, and the final interpretation results. This proposal is mainly based on findings in ERP studies on language processing. The last decade has seen an increasing number of ERP studies on syntactic processing, triggered by the discovery some 10 years ago of an ERP effect to syntactic violations that was clearly different from the well-known N400 effect to semantic violations (Hagoort et al., 1993; Osterhout and Holcomb, 1992).

These studies have been followed up by a large number of ERP-studies on syntactic processing that have provided a wealth of data. Here I will connect the known syntax-related ERP effects to a computational model of parsing (Vosse and Kempen, 2000). This model was developed to account for a large portion of behavioral findings in the parsing literature and for deficit patterns in aphasic patients. In the context of considerations based on brain organization it makes the right distinction between lexicalized patterns and a unification component. However, before discussing the model, I will first discuss the relevant ERP-results, and then present some data that are incompatible with a syntax-first model. Later in this chapter, I will indicate how the model connects to relevant brain areas for syntactic processing, and to data from lesion studies.

\subsection{Language-relevant ERP effects}

The electrophysiology of language as a domain of study started with the discovery by Kutas and Hillyard (1980) of an ERP component that seemed especially sensitive to semantic manipulations. Kutas and Hillyard observed a negative-going potential with an onset at about $250 \mathrm{~ms}$ and a peak around $400 \mathrm{~ms}$ (hence the 
N400), whose amplitude was increased when the semantics of the eliciting word (i.c. socks) mismatched with the semantics of the sentence context, as in $\mathrm{He}$ spread his warm bread with socks. Since 1980 , much has been learned about the processing nature of the $\mathrm{N} 400$ (for extensive overviews, see Kutas and $\mathrm{Van}$ Petten, 1994; Osterhout and Holcomb, 1995). As Hagoort and Brown (1994) and many others have observed, the N400 effect does not depend on a semantic violation. Subtle differences in semantic expectancy as between mouth and pocket in the sentence context "Jenny put the sweet in her mouth/pocket after the lesson" can modulate the N400 amplitude (Figure 2; Hagoort and Brown, 1994).

The amplitude of the $\mathrm{N} 400$ is most sensitive to the semantic relations between individual words, or between words and their sentence and discourse context. The better the semantic fit between a word and its context, the more reduced the amplitude of the $\mathrm{N} 400$. Modulations of the $\mathrm{N} 400$ amplitude are generally viewed as directly or indirectly related to the processing costs of integrating the meaning of a word into the overall meaning representation that is built up on the basis of the preceding language input (Brown and Hagoort, 1993; Osterhout and Holcomb, 1992). This holds equally when the preceding language input consists of a single word, a sentence, or a discourse, indicating that semantic unification operations might be similar in word, sentence, and discourse contexts (Van Berkum et al., 1999b). In addition, recent evidence indicates that sentence verification against world knowledge in long-term memory modulates the $\mathrm{N} 400$ in the same way (Hagoort et al., 2004).

In recent years a number of ERP studies have been devoted to establishing ERP effects that can be related to the processing of syntactic information. These studies have found ERP effects to syntactic processing that are qualitatively different from the $\mathrm{N} 400$. Even though the generators of these effects are not yet well determined and not necessarily language-specific (Osterhout and Hagoort, 1999), the existence of qualitatively distinct ERP effects to semantic and syntactic processing indicates that the brain honouts the distinction between semantic and syntactic unification operations. Thus, the finding of qualitatively distinct ERPeffects for semantic and syntactic processing operations supports the claim that these two leveis of language processing are domain specific. However, domain specificity should not be confused with modularity (Fodor, 1983). The modularity 
Jenny put the sweet in
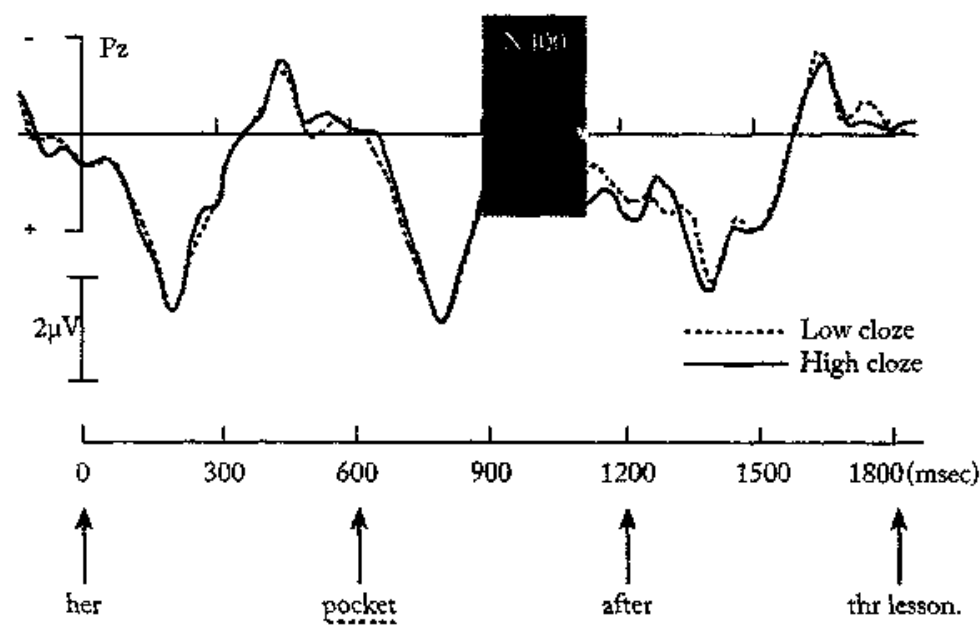

Figure 2. Madulation of the N400-amplitude as a result o, a manipulation of the semantic fit between a lexical item and its sentente context. The grand-average waveform is shown for electrode site Pz (pariatal midline), for the best fitting word (High Cloxe; solid line), and a w'rd that is less expected in the given sentence context (Low Cloze; dashed line). The sentences were visually pretsented word by word, every $600 \mathrm{~ms}$. In the figure the critical qoords are preseded and followed by one word. The critical word is presented at 600 ms on the time axis. Negativity is up. (Adapted from Hagoort and Brown (1994). Copyright (1) 1994 Erlbaum, reprinted by permission).

thesis makes the much stronger claim that domain-specific levels of processing operate autonomously without interaction (informational encapsulation). Although domain-specificity is widely assumed in models of language processing, there is much less agreement about the organization of the cross-talk between different levels of sentence processing (cf. Boland and Cutler, 1996).

ERP studies on syntactic processing have reported a number of ERP effects related to syntax (for an overview, see Hagoort et al., 1999). The two most salient syntax-related effects are an anterior negativity, also referred to as LAN, and a more posterior positivity, here referred to as P600/SPS.

$L A N$. A number of studies have reported negativities that are different from the $\mathrm{N} 400$, in that they ustally show a more frontal maximum (but see Münte et al., 1997), and are sometimes larger over the left than the right hemisphere, although in many cases the distribution is bilateral (Hagoort et al., 2003b). More- 
over, the conditions that elicit these frontal negative shifts seem to be more strongly related to syntactic processing than to semantic integration. Usually, LAN effects occur within the same latency range as the N400, that is between 300 and 500 ms post-stimulus (Friederici et al., 1996; Kluender and Kutas, 1993; Münte et al., 1993; Osterhout and Holcomb, 1992; Rösler et al., 1993). But in some cases the latency of a left-frontal negative effect is reported to be much earlier, somewhere between approximately 100 and 300 ms (Friederici, 2002; Friederici et al., 1993; Neville et al., 1991).

In some studies LAN effects have been reported to violations of word-category constraints (Friederici et al., 1996; Hagoott et al., 2003b; Münte et al., 1993). That is, if the syntactic context requires a word of a certain syntactic class (e.g. a noun in the context of a preceding article and adjective), but in fact a word of a different syntactic class is presented (e.g. a verb), early negativities are observed. Fiederici and colleagues (e.g. Friederici, 1995; Friederici et al., 1996) have tied the early negativities specifically to the processing of word-category information. However, in other studies similar early negativities are observed with number, case, gender, and tense mismatches (Münte and Heinze, 1994; Münte et al., 1993). In these violations the word category is correct but the morphosyntactic features are wrong. Friederici (2002) has recently attributed the very early negativities that occur approximately between 100 and $300 \mathrm{~ms}$ (ELAN) to violations of word category, and the negativities between 300 and $500 \mathrm{~ms}$ to morphosyntactic processing.

LAN effects have also been related to verbal working memory in connection to filler-gap assignment (Kluender and Kutas, 1993). This working memory account of the LAN is compatible with the finding that lexical, syntactic and referential ambiguities seem to elicit very similar frontal negativities (Hagoort and Brown, 1994; Van Berkum et al., 1999a; Kaan and Swaab, 2003b; King and Kutas, 1995). Lexical and referential ambiguities are clearly not syntactic in nature, but can be argued to tax verbal working memory more heavily than sentences in which lexical and referential ambiguities are absent. Syntactic ambiguities might atso tax working memory stronger than their unambiguous counterparts. Future research should indicate whether or not these two functionally distinct classes of LAN effects can be dissociated at a more fine-grained level of electrophysiological analysis. 
P600/SPS. A second ERP effect that has been related to syntactic processing is a later positivity, nowadays referred to as P600/SPS (Coutson et al., 1998; Hagoott et al., 1999; Osterhout et at., 1997). One of the antecedent conditions of P600/ SPS effects is a violation of a syntactic constraint. If, for instance, the syntactic tequirement of number agreement between the grammatical subject of a sentence and its finite verb is violated (see (1), with the critical verb form in italics; the * indicates the ungrammaticality of the sentence.), a positive-going shift is elicited by the word that zenders the sentence ungrammatical (Hagoort et al., 1993). This positive shift starts at about $500 \mathrm{~ms}$ after the onset of the violation and usually lasts for at least $500 \mathrm{~ms}$. Given the polarity and the latency of its maximal amplitude, this effect was originally referred to as the P600 (Osterhout \& Hoicomb, 1993) or, on the basis of its functional characteristics, as the Syntactic Positive Shift (SPS; Hagoort et al., 1993).

(1) The spoilt child tbrow the toy on the ground.

An argument for the independence of this effect from possibly confounding semantic factors is that it also occurs in sentences where the usual semantic/pragmatic constraints have been removed (Hagoort and Brown, 1994). This results in sentences like (2a) and (2b) where one is semantically odd but grammatically correct, whereas the other contains the same agreement violation as in (1):

(2)a. The boiled watering-can smokes the telephone in the cat.

b. *The bolled watering-can smoke the telephone in the cat.

If one compares the ERPs to the italicized verbs in (2a) and (2b) a P600/SPS effect is visible to the ungrammatical verb form (Figure 3). Despite the fact that these sentences do not convey any conventional meaning, the ERP effect of the violation demonstrates that the language system is nevertheless able to parse the sentence into its constituent parts.

Similar P600/SPS effects have been reported tor a broad range of syntactic violations in different languages (English, Dutch, German), including phrase-structure violations (Hagoort et al., 1993; Neville et al., 1991: Osterhout and Holcomb, 


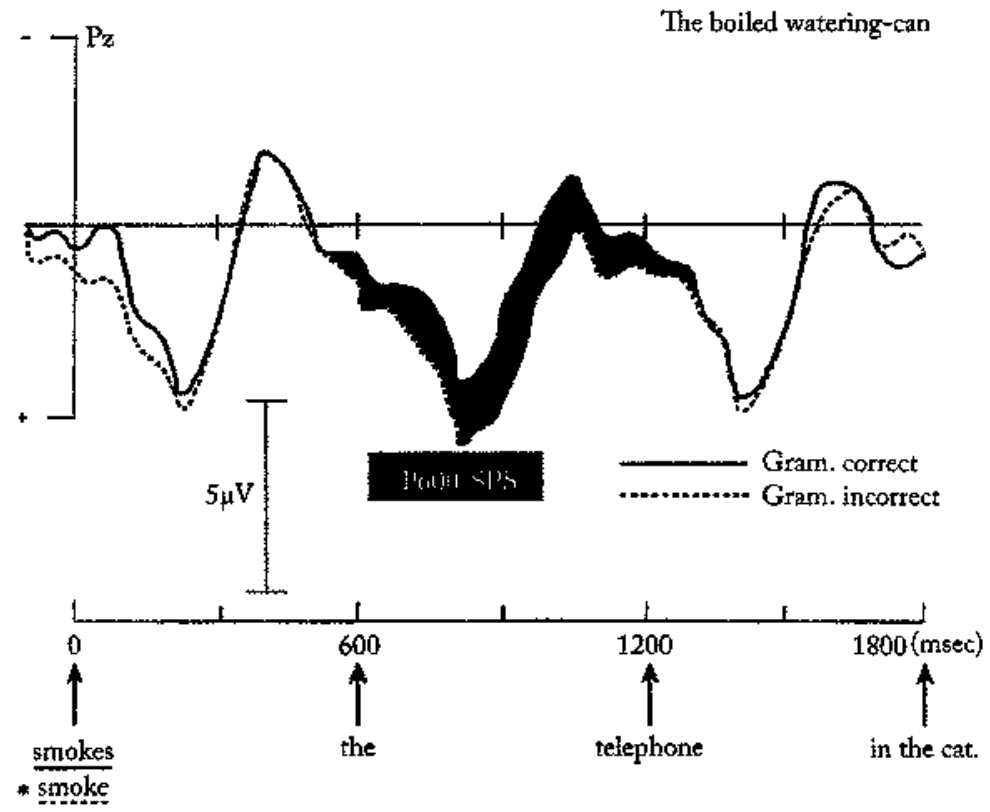

Figure 3. ERPS to visually presented syntactic prose sentences. These are sentences without a coherent sementic interpretation. A P600/SPS is elicited by a violation of the required number agreement between the subject-noun phrase and the finite verb of the sentence. The ateraged waveforms for the grammatically correct (solid line) and the granmatically incortect (dasbed line) words are shown for electrode site $P_{z}$ (parietal midline). The word that renders the sentence ungrammatical is presented at $O$ ms on the time axis. The waveforms show the ERPs to this and the following two wards. Words were presented word by word, witb an interval (SOA) of $600 \mathrm{~ms}$. Negativity is plotted upwards (Adapted fran Hagoont and Brown (1994). Copyright (S 1994 Erlbatum, reprinted by permission.)

1992), subcategorization violations (Ainsworth-Darnell et al., 1998; Osterhout et al., 1997; Osterhout et al., 1994), violations in the agreement of number, gender, and case (Coulson et al., 1998; Hagoort et al., 1993; Münte et al., 1997; Osterhout, 1997; Osterhout and Mobley, 1995), violations of subjacency (McKinnon and Osterhout, 1996; Neville et al., 1991), and of the empty-category principle (McKinnon and Osterhout, 1996). Recently, a P600/SPS is also repotted in relation to thematic role animacy violations (Kuperberg, Sitnikova, Caplan, \& Holcomb, 2003). Moreover, a P600/SPS can be found with both written and spoken input (Friederici et al., 1993; Hagoott and Brown, 2000a; Osterhout and Holcomb, 1993). 
In summary, two classes of syntax-related ERP effects have been consistently reported. These two classes differ in their polarity, topographic distribution, and in their latency characteristics. In terms of latency, the first class of effects is an ante-

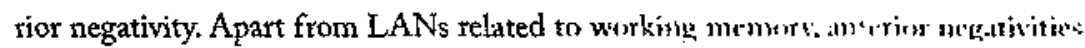
are mainly seen to syntactic violations. In a latre $1, \ldots, \ldots, \ldots$

which are not only elicited by syntactic viesti:: .

formed sentences that vary in complevit: 1

the number of alternative syntactic s1, $\ldots$. ,

a particular position in the sentence in:

Van Berkum et al., 1999a). Since thes' in..

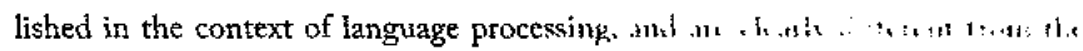
$\mathrm{N} 400$ effect, the need arises to account for these effects in terms of a well-defined model of language processing.

Broadly speaking, models of sentence processing can be divided into two types. One type of model assumes a precedence of syntactic information. That is, an initial syntactic structure is constructed before other information (e.g. lexical-seman" tic, discourse information) is taken into account (Frazier, 1987). I will refer to this type of model as a syntax-first model. The alternative broad set of models claims that the different information types (lexical, syntactic, phonological, pragmatic) are processed in parallel and influence the interpretation process incrementally, that is as soon as the relevant pieces of information are avalable (Jackendoff, 2002; Marslen-Wilson, 1989; Zwitserlood, 1989). I will refer to this type of model as the immediacy model. Overall, the behavioral data, although not decisive, are more in favor of the second type of model than the first. I will first present some recent ERP data that are more compatible with the immediacy model.

\subsection{Evidence against the syntax-first principle}

The strong version of a syntax-first model of sentence processing assumes that the computation of an initial syntactic structure precedes semantic unification operations, because structural information is necessary as input for thematic role assignment. In other words, if no syntactic structure can be built up, semantic unification will be impaired. Recent electrophysiological evidence has been taken as evidence for this syntax-first principle (Friederici, 2002). Alternative models (Marslen-Wil- 
son and Tyler, 1980; MacDonald et al., 1994) claim that semantic and syntactic information are immediately used when becoming available without a priority for syntactic information over other information types.

ERP evidence for an autonomous syntax-first model in sentence processing is derived from a series of studies in which Friederici and colleagues found an ELAN to auditorily presented words whose prefix is indicative of a word category violation. For instance, Hahne and Jescheniak (2001) and Friederici et al. (1993) had their subjects listen to sentences such as "Die Birne wurde im gefflückl" ("The pear was being in-the plucked) or "Die Freund wurde im besucbt" ("The friend was being in-the visited "), where the prefixes "ge-" and "be-" in combination with the preceding auxiliary "wurde" are indicating a past participle where the preposition "im" requires a noun. In this case a very early (between 100 and $300 \mathrm{~ms}$ ) left anterior negativity is observed that precedes the N400 effect.

Although this evidence is compatible with a syntax-first model, it is not necessarily incompatible with an immediacy model of sentence processing. As long as word category information can be derived earlier from the acoustic inpur than semantic information, as was the case in the above-mentioned studies, the immediacy model predicts that it will be used as it comes in. The syntax-first model, however, predicts that even in cases where word category information comes in later than semantic information, this syntactic information will nevertheless be used earlier than semantic information in sentence processing. Van den Brink and $\mathrm{Ha}$ goort (2004) designed a strong test of the syntax-first model, in which semantic information precedes word category information. In many languages information about the word category is often encapsulated in the suffix rather than the prefix of a word. In contrast to an immediacy model, a syntax-first model would in such a case predict that semantic processing (more in particular, semantic unification) is postponed until after the information about the word category has become available.

In their study Van den Brink and Hagoort (2004) compared correct Dutch sentences (see 3a) with their anomalous counterparts (see 3b) in which the critical word (italicized in $3 \mathrm{a} / \mathrm{b}$ ) was both a semantic violation in the context and had the incorrect word category. However, in contrast to the experiments by Friederici and colleagues, word category information was encoded in the suffix "-de". 
(3)a. "Het vrouwtje veegde de vloer met een oude bezem gemaakt van twijgen" ("The woman wiped the floor with an old broom made of twigs") b." "Het vrouwtje veegde de vloer met een oude kliederde gemaakt van twijgen" ("The woman wiped the floor with an old messed made of twigs")

Figure 4 shows the waveform of the spoken verb form "kliederde" (messed). This verb form has a duration of approximately $450 \mathrm{~ms}$. The stem already contains part of the semantic information. However, the onset of the suffix "-de" is at about 300 $\mathrm{ms}$ into the word. Only at this point it will be clear that the word category is a verb, and not a noun as required by the context. We define this moment of deviation from the correct word category as the Category Violation Point (CVP), because only at this time is information provided on the basis of which it can be recognized as a verb, which is the incorrect word category in the syntactic context. Although in this case semantic information can be extracted from the spoken signa' before word category information, the syntax-first model predicts that this semantic information can not be used for semantic unification until after the assignment of word category.

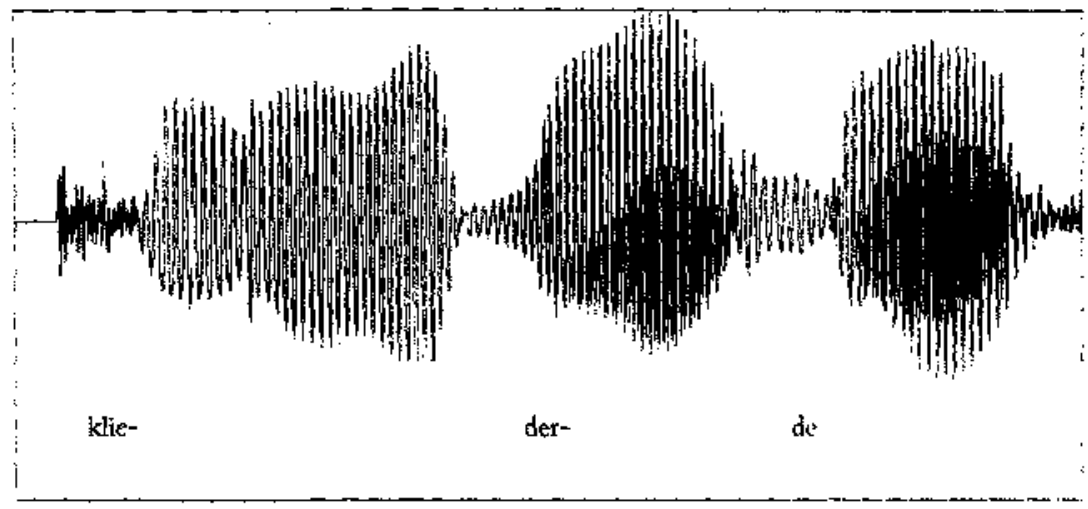

Figure 4. A wav'eform of an aconstit foken of the Dutch werb form "kliederde" (messed). Tbe suffix "de indicates past tense. The total duration of the acoust is token is apprctimatet? $450 \mathrm{~ms}$. The onset of the suffix "-di" is at approximately $300 \mathrm{~ms}$. Only after $300 \mathrm{~ms}$ of signal, the aiowitic token ian be classified as $a$ wetb. Thus, for a context that toes not allow a terb in that position, she Categery Vitolation Point (CVP) is at $300 \mathrm{~ms}$ into the teerb (set text). 
Figure 5 shows the averaged waveforms that are time-locked to the CVP for two frontal sites where usually the ELAN is observed, and two posterior sites that are representative of $\mathrm{N} 400$ effects. As can be seen, the $\mathrm{N} 400$ effect clearly precedes the ELAN in time. Whereas the ELAN started at approximately $100 \mathrm{~ms}$ after the CVP, the N400 effect was already significant before the CVP. To my knowledge, this is the clearest evidence so far for the claim that semantic unification can start before word category information is provided. This is strong evidence for the immediacy assumption: information available in the signal is immediately used for further processing. In contrast to what a strong version of the syntax-first model predicts, semantic unification does not need to wait until an initial structure is built on the basis of word category information. Only when a syntax-first model allows prediction of word category, it could claim that this prediction was only falsified at the CVP, and thus initially semantic unification could be started up. However, this weaker version of a syntax-first model has given up the characteristic of bottom-up priority and assumes an interaction between syntactic context and lexical processing. One can then ask which feature of the processing architecture guarantees that interaction between context and lexical processing is restricted to syntax.

In summary, the evidence so far indicates that distinct ERP effects are observed for semantic integration (N400) and syntactic analysis (E)LAN, P600/ SPS). The ERP data presented are evidence against a syntax-first model of sentence processing. Rather, as soon as semantic or syntactic information is available, it is used for the purpose of interpretation. This is in line with the assumptions of the immediacy model. The triggering conditions of the syntax-related ERP effects are becoming more clear. Apart from the LAN effects related to working memory, so far (E)LAN effects have mainly been seen to syntactic violations. These violations can be word category violations that are sometimes seen early (ELAN), but they can also be morphosyntactic violations that are usually observed within the same time frame as the N400 effects (300-500 ms). The Anterior Negativities are normally followed by a P600/SPS. In contrast to the (E)LAN, the P600/SPS is not only seen to syntactic violations, but is also seen to syntactically less preferred structures (i.e. in the case of syntactic ambiguity; Van Berkum et al.; 1999a; Oster* hout et al., 1994), and to syntactically more complex sentences (Kaan et al., 2000). 
In many cases, the P600/SPS occurs without a concomitant early negativity. For straightforward syntactic violations the distribution of the P600/SPS seems to be more posterior than the P600/SPS reported in relation to syntactic anbiguity resolution and syntactic complexity (Hagoort et al., 1999; Kaan and Swaab, 2003a, 2003b).
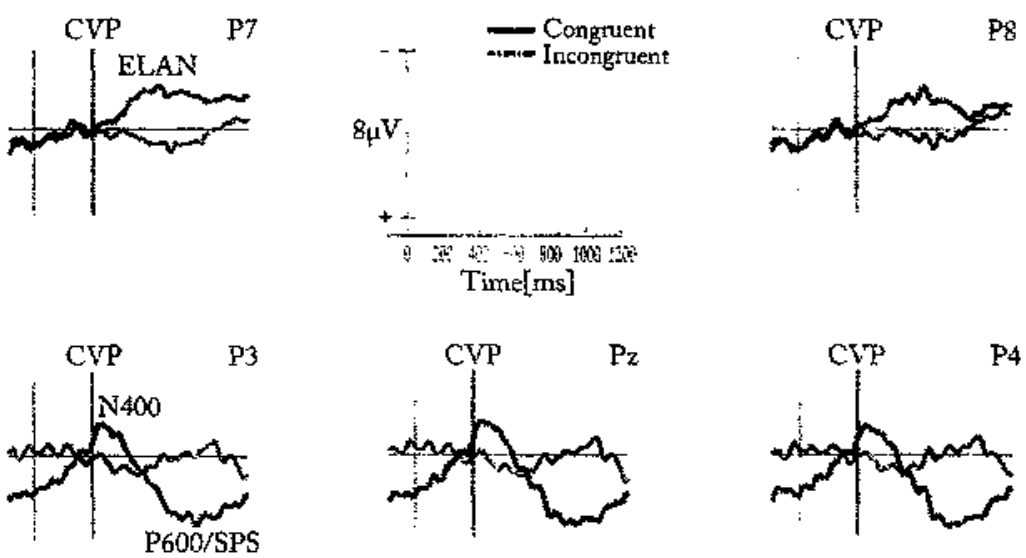

Figure 5. Connected speech. Grand azerage ERP from two frontal electrode sites (F-, F8), and tbret posterior electrode sites ( $\left.P X_{2}, P 3, P 4\right)$, to critical words that acere semantically and syntactically ongruent with the sentence context (Congruent: solid line), or semantically and syntactically incongruent (Incongruent: alternating dashed/dotted line). Grond average waveforms quere computed after time lacking on a trial-by-trial basis to tbe moment of word category winlation (CVP. Categary Violation Point). The baseline was determined by ateraging in the 180 to $330 \mathrm{~ms}$ interval, corrisponding to a $150 \mathrm{~ms}$ interval preteding the CVP in the incongruent comdition. The fine axis is in milliseconds, negativity is up. The ELAN is visible over the fwo frontal sites, the N4OO and the P600'SPS over the three posterior sites. Tbe onset of the El. $A N$ is at $100 \mathrm{~ms}$ after the ClP, the onset of the $N 400$ effect precedes the CVP by approximately $10 \mathrm{~ms}$ (after $\mathrm{V}$ an den Brink 5 Hagart, 2004 ).

\subsection{The Unification Model}

The increasing number of ERP studies on syntactic processing in the last decade have resulted in a substantial amount of data that are in need of a coherent, overall account. I will propose an explicit account of syntax-related ERP effects based on a computational model of parsing developed by Vosse and Kempen (2000), here referred to as the Unification Model. This proposal is certainly not the end stage, but only a beginning. Both the model needs to be adapted and the account of the ERP data needs to be refined. Nevertheless I believe that progress will only be 
made if we attempt to connect not only the behavioral data but also data from electrophysiology and neuroimaging to explicit computational accounts. I will first describe the general architecture of this model.

According to the Unification Model each word form in the lexicon is associated with a structural frame. This structural frame consists of a three-tiered unordered tree, specifying the possible structural environment of the particular lexical item (see Figure 6; for details concerning the computation of word order, see Harbusch and Kempen, 2002).
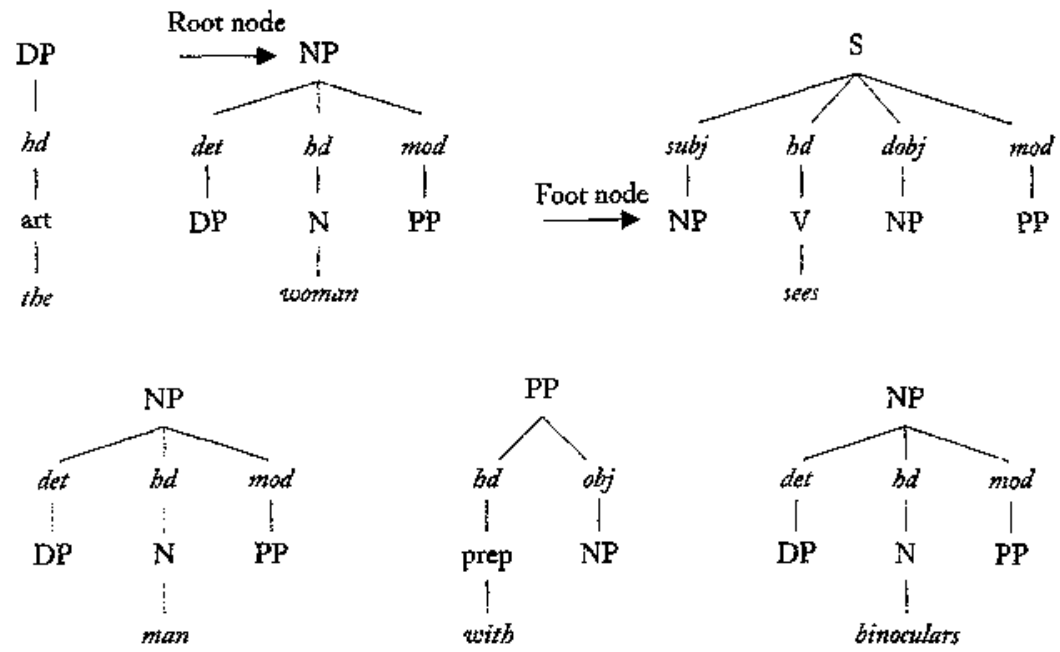

Figure 6. The unification operation of two lexically specified syntactic frames. The unification takes place by linking the root node NP to an available foot node of the same category. The number 2 indicates that this is the second link that is formed during on-line prosessing of the sentence "The woman sees the man with the binoculars".

The top layer of the frame consists of a single phrasal node (e.g., NP).

This so-called root node is connected to one or more functional nodes (e.g., Subject, Head, Direct Object) in the second layer of the frame. The third layer contains again phrasal nodes to which lexical items or other frames can be attached. 


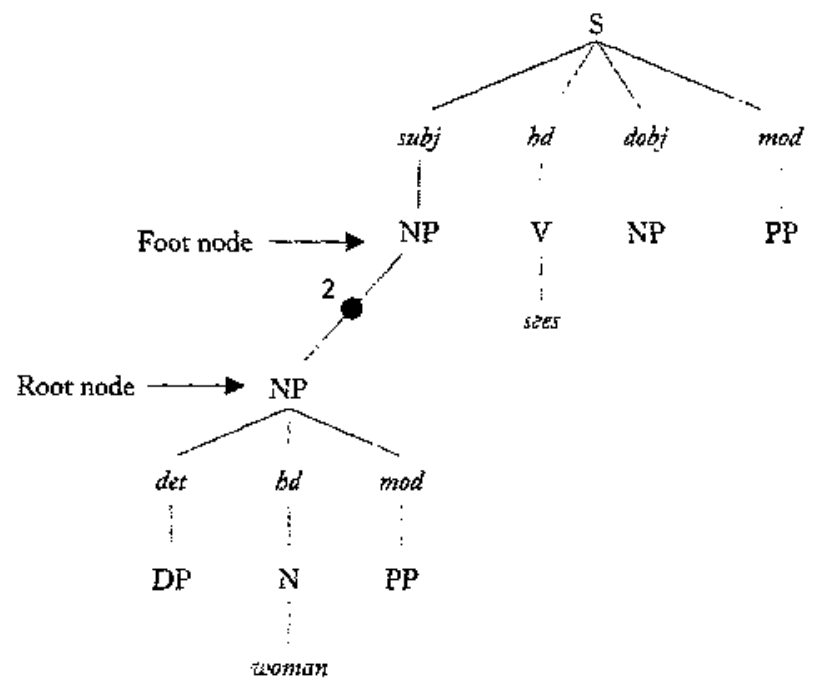

Figure 7. The unification operation of tut' lexically specified symtactic frames. The anification takes place by linking the root node NP to an arailable foot node of the same category. The number 2 indicates that this is the second link that is formed dwing on-line protessing of the sentente "The woman sees the man with the binoculars".

This parsing account is 'lexicalist' in the sense that all syntactic nodes (e.g., $S_{\text {; }}$ NP, VP, N, V, etc.) are retrieved from the mental lexicon. In other words, chunks of syntactic structure are stored in memory. There are no syntactic rules that introduce additional nodes. In the on-line comprehension process, structural frames associated with the individual word forms incrementally enter the unification workspace. In this workspace constituent structures spanning the whole utterance are formed by a unification operation. This operation consists of linking up lexical frames with identical root and foot nodes (see Figure 7), and checking agreement features (number, gender, person, etc.). It specifies wl it Jackendoff (2002) refers to as the only remaining "grammatical rule" UNIFY PIECES.

The resulting unification links between lexical frames are formed dvnamically: which implies that the strength of the unification links varies over time until a state of equilibrium is reached. Due to the inherent ambiguity in ratural language, alternative unification candidates will usually be avaikable at any point in the parsing process. That is, a particular root node (e.g., PP) often finds more than one matching foot node (i.c. PP) with which it can form a unification link (see Figure 
8).

Ultimately, one phrasal configuration results. This requires that among the alternative unification candidates only one remains active. The required state of equilibrium is reached through a process of lateral inhibition between two or more alternative unification links. In general, due to gradual decay of activation more recent foot nodes will have a higher level of activation than the ones that entered the unification space earlier. This is why the likelihood of an attachment of the PP into the syntactic frame of the verb "sees" is higher than into the syntactic frame for "woman" (see Figure 7). In addition, strength levels of the unification links can vary in function of plausibility (semantic) effects. For instance, if instrumental modifiers under S-nodes have a slightly higher default activation than instrumental modifiers under an NP-node, lateral inhibition can result in overriding the re-

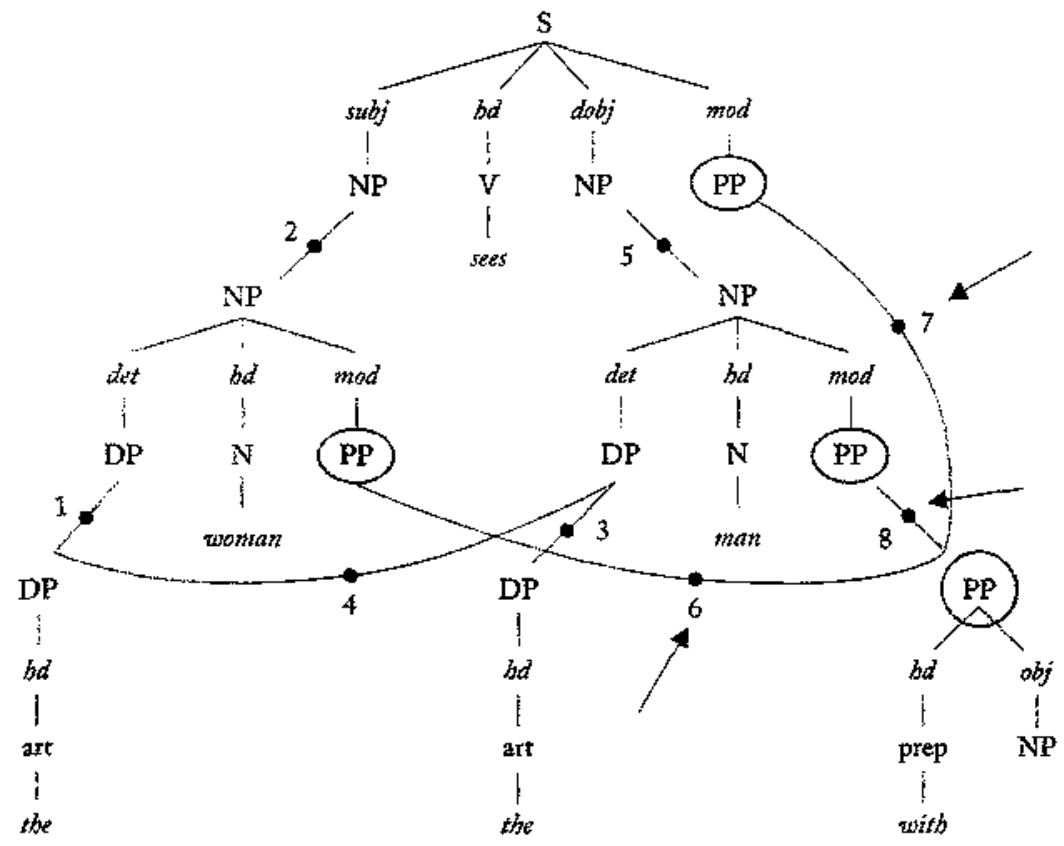

Figure 8. Lateral inbibition between tbree different $P P_{\text {-foot nodes that are candidate unification sites }}$ for the PP-root nodl of the preposition "with". The three possible unification links are indicated by arrows. Lateral inbibition between these tbree possible unifications $(6,7$, and 8$)$ ult imately results in one unification that wins the competition and remains active. 
cency effect. For our example sentence (see Figure 8) it means that the outcome of lateral inhibition is that the PP may be linked to the S-frame (Unification link 7) rather than to the more recent NP-node of "man" (U-link 8) (for the details, see Vosse and Kempen, 2000).

The Unification Model accounts for sentence complexity effects known from behavioral measures, such as reading times. In general, sentences are harder to analyze syntactically when more potential unification links of similar strength enter into competition with each other. Sentences are easy when the number of U-links is small and of unequal strength.

The advantage of the Unification Model is that (i) it is computationally explicit, (ii) accounts for a large series of empirical findings in the parsing literature (but presumably not for all the locality phenomena in Gibson, 1998) and in the neuropsychological literature on aphasia, (iii) belongs to the class of lexicalist parsing models that have found increasing suppott in recent years (Bresnan, 2001; Jackendoff, 2002; Joshi and Schabes, 1997; MacDonald et al., 1994).

This model also nicely accounts for the two classes of syntax-related ERP-effects reported in this and many other studies. In the Unification Model, binding (unification) is prevented in two cases. One case is when the root node of a syntactic building block (e.g., NP) does not find another syntactic building block with an identical foot node (i.c. NP) to bind to. The other case is when the agreement check finds a serious mismatch in the grammatical feature specifications of the root and foot nodes. The claim is that a (left) anterior negativity (AN) results from a failure to bind, as a result of a negative outcome of the agreement check or a failure to find a matching category node. For instance, the sentence "The woman sees the man because with the binoculars" does not result in a completed parse, since the syntactic frame associated with “becautse" does not find unoccupied (embedded) S-root nodes that it can bind. As a result, unification fails.

In the context of the Unification Model, I propose that the P600/SPS is related to the time it takes to establish unification links of sufficient strength. The tirse it takes to build up the unification links until the required strength is reached, is affected by ongoing competition between alternative unification options (syntactic ambiguity), by syntactic complexity, and by semantic influences. The amplitude of the P600/SPS is modulated by the amount of competition. Competition is re- 
duced when the number of alternative unification options is smaller, or when lexical, semantic or discourse context biases the strengths of the unification links in a particular direction, thereby shortening the duration of the competition. Violations result in a P600/SPS as long as unification attempts are made. For instance, a mismatch in gender or agreement features might still result in weaker unification in the absence of alternative options. However, in such cases the strength and build-up of U-links will be affected by the partial mismatch in syntactic feature specification. Compared to less complex or syntactically unambiguous sentences, in more complex and syntactically ambiguous sentences it takes longer to build up U-links of sufficient strength. The latter sentences, therefore, result in a P600/SPS in comparison to the former ones.

In summary, it seems that the Unification Model provides an acceptable preliminary account for the collective body of ERP data on syntactic processing. Moreover, it does not assume a syntax-first architecture. It is, therefore, a better account of the empirical data, both behavioral and electrophysiological, than models that assume a syntax-first phase.

\section{Semantic unification}

Next to syntactic unification, semantic unification operations have to take place. Neuropsychological patient studies as well as data from neuroimaging studies suggest that semantic representations might be distributed with the involvement of areas that support the most salient aspects of a concept (e.g., visual, kinesthetic, linguistic/propositional) (Allport, 1985; Saffran \& Sholl, 1999). Context can differentially activate/select the saliency of meaning aspects (e.g., as in "The girl gave a wonderful performance on the old piano." vs. "Four men were needed to transport the old piano."). At the same time the semantic aspects retrieved on the basis of lexical access have to be integrated into a coherent interpretation of a multiword utterance. This I will refer to as semantic unification. It turns out that left lateral prefrontal cortex is also crucial for semantic unification (see below). Bindingrelevant areas within the left prefrontal cortex (LPC) might overlap, at least to some degree, for syntactic and semantic unification. But there is also evidence that 
semantic unification might involve more ventral areas (especially Brodmann's area 47) than syntactic unification. More research is needed to determine commonalities and differences in LPC between areas involved in phonological, syntactic and semantic unification. However, the qualitative differences between ERP effects of semantic (N400) and syntactic (LAN, P600) uniffcation suggest that the brain honours the distinction between these two types of unification operations.

\subsection{The level of semantic unification: sentence vs. discourse}

A central issue for semantic unification is whether or not a semantic representation at the sentence-level is built up first, before in a second step semantic information is integrated into a discourse model. For instance, in their blueprint of the listener, Cutler \& Clifton (1999) assume that based on syntactic analysis and thematic processing, utterance interpretation takes place first, before in a next processing step integration into a discourse model follows. Kintsch (Kintsch, 1998; Ericsson \& Kintsch, 1995) has made similar claims. To investigate this issue, we conducted an ERP study to investigate how and when the language comprehension system relates an incoming word to semantic representations of the unfolding local sentence and the wider discourse (Van Berkum et al., 1999b). In the first experiment, subjects were presented with short stories, of which the last sentence sometimes contained a critical word that was semantically anomalous with respect to the wider discourse (e.g., Jane told the brotber that be was exceptionally slow in a discourse context where he had in fact been very quick). Relative to a discoursecoherent counterpart (e.g., quick), these discourse-anomalous words elicited a large N400 effect (i.e., a negative shift in the ERP that began at about 200 to $250 \mathrm{~ms}$ after word onset and peaked around $400 \mathrm{~ms}$ )

Next to the discourse-related anomalies, sentence-semantic anomaly effects were elicited under comparable experimental conditions. We found that the ERP effects elicited by both types of anomalies were highly similar. Relative to their coherent counterparts, discourse- and sentence-anomalous critical words elicited an N400 effect with an identical time-course and scalp topography (Figure 9). The similarity of these effects, particularly in polarity and scalp distribution, is compatible with the claim that they reflect the activity of a largely overlapping or identical set of underlying neural generators, indicating similar functional processes. 

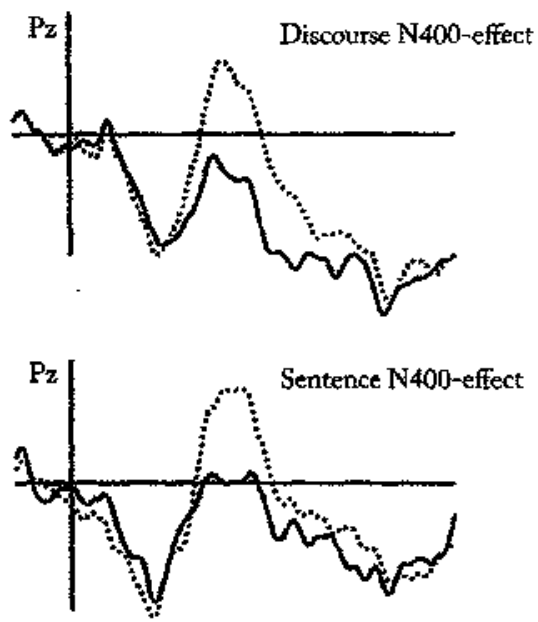

Figure 9. N400 ffects triggered by discourse-related and sentence-related anomalies. Waveforms are presented for a representative electrode site. The latencies of the $N 400$ effect in discourse and sentence contexts (both onset and peak latencies) are the same. (after Van Berkum et al. 1999b).

In summary, there is no indication that the language comprehension system is slower in relating a new word to the semantics of the wider discourse than in relating it to local sentence context. Our data clearly do not support the idea that new words are related to the discourse model after they have been evaluated in terms of their contribution to local sentence semantics. The speed with which discourse context affects processing of the current sentence appears to be at odds with recent estimates of how long it would take to retrieve information about prior discourse from long-term memory. In the Van Berkum et al's materials, the relative coherence of a critical word usually hinged on rather subtle information that was implicit in the discourse and that required considerable inferencing about the discourse topic and the situation it described. Kintsch (Kintsch, 1998; Ericsson \& Kintsch, 1995) has suggested that during on-line text comprehension, such subtle discourse information is not immediately available and must be retrieved from "longterm working memory" when needed. This is estimated to take some 300 to $400 \mathrm{~ms}$ at least. However, the results of our experiments suggest that the relevant discourse information can be brought to bear on local processing within at most 200 to $250 \mathrm{~ms}$. 
The observed identity of discourse- and sentence-level N400 effects is most parsimoneously accounted for in terms of a processing model that abandons the distinction between sentence- and discourse-level semantic unification. This is compatible with the notion of common ground (Stalnakez, 1978; Clark, 1996). The analysis of Clark clearly demonstrates that the meaning of linguistic utterances cannot be determined without taking into account the knowledge that speaker and listener share and mutually believe they share. This common ground includes a model of the discourse itself, which is continually updated as the discourse unfolds. If listeners and reałers always immediately evaluate new words relative to the discourse model and the associated information in common ground (i.e., immediately compute "contextual meaning"), the identity of the ERP effects generated by sentence- and discourse anomalies has a natural explanation. With a single sentence, the relevant common ground only inciudes whatever discourse and world knowledge has just been activated by the sentence fragment presented so far. With a sentence presented in discoirse context, the relevant common ground will be somewhat richer, now also including information elicited by the specific earlier discourse. But the process that maps incoming words onto the relevant common ground can run into trouble either way. The N400 effects obsenved in the Van Berkum et al. study (1999)) reflect the activity of this unified unification process. Of course, this is not to deny the relevance of sentential structure for semantic interpretation. In particulat, how the incoming words are related to the discourse model is co-constrained by sentence-level syntactic devices (such as word order, case marking, local phrase structure, or agreement), and the associated mapping onto thernatic roles. However, this is fully compatible with the claim that there is no separate stage during which word meaning is exclusively evaluated with respect to "local sentence meaning," independent of the discourse context in which that sentence occurs.

\section{The neural implementation of unification in language}

In the context of the language system, the binding problem refers to the following issue: How is information that is incrementally retrieved from the mental lexicon 
unified into a coherent overall interpretation of a multi-word utterance? Most likely, unification needs to take place at the conceptual, syntactic and phonological levels, as well as between these levels (Jackendoff, 2002). So far I discussed the features of the cognitive architecture for syntactic and semantic unification. In this section I will argue that the left inferioz prefrontal cortex might have the characteristics necessary for performing the unification operations at the different levels of the language system.

One requirement for solving the binding problem for language is the avallability of cortical tissue that is particularly suited for maintaining information on-line, while unification operations take place. Prefrontal cortex seems to be especially well-suited for doing exactly this. Areas in prefrontal cortex are able to hold information on-line (Mesulam, 2002), and to select among competing alternatives (Thompson-Schill, D'Esposito, \& Kan, 1999). Electrophysiological recordings in the macaque monkey have shown that this area is important for sustaining information triggered by a transient event for many seconds (Miller, 2000). This allows prefrontal cortex to establish tnifications between pieces of information that are perceived or retrieved from memory at different moments in time.

I will make some tentative suggestions "about how the different components of the Unification Model for syntactic unification that I discussed above could be connected to our fonowledge about the neural architecture. This proposal is not yet explicitly tested, but as I will argue, it makes good sense in the light of our current knowledge about the contributions of the areas involved. In a recent meta-analysis of 28 neuroimaging studies, Indefrey (2003) found two areas that were critical for syntactic processing, independent of the input modality (visual in reading, auditory in speech). These two supramodal areas for syntactic processing were the left posterior superior temporal gyrus and the left posteriot inferior frontal cortex.

As is known from lesion studies in aphasic patients, lesions in different areas of left perisylvian cortex can result in syntactic processing deficits in sentence comprehension (Caplan, Hildebrandt, \& Makris, 1996). The idea that modalityindependent grammatical knowledge was mainly represented in Broca's area (Zurif, 1998) has thus been proven to be incorrect. At the same time, the teft posterior temporal cortex is known to be involved in lexical processing (Indefrey \& Cutler, 2004). In connection to syntactic unification, this part of the brain might be im- 
portant for the retrieval of the syntactic frames that are stored in the lexicon.

The unification space where individual frames are connected into a phrasal configuration for the whole utterance might be localized in the left frontal part of the syntax-relevant network of brain areas. One of the main specializations of prefrontal cortex is the holding on-line and binding of information (Mesulam, 2002). It might be the right area for providing the computational resources for binding together the lexical-syntactic frames through the dynamics of creating unification links between them (cf. Duncan and Miller, 2002). It thus seems that the components of the Unification Model and the areas known to be crucial for syntactic processing can be connected in a relatively natural way, with left superior temporal cortex relevant for storage and retrieval of syntactic frames, and the left prefrontal cortex important for binding these frames together.

The need for combining independent bits and pieces into a single coherent percept is not unique for syntax. Models for semantic/conceptual unification and phonological unification could be worked out along similar lines as the Unification Model for syntax. Recent neuroimaging studies suggest that parts of prefrontal cortex in and around Broca's area rnight be involved in conceptual and phonological unification, with Brodmann Areas (BA) 47 and 45 involved in semantic unification, BA 45 and 44 in syntactic unification, and BA 44 and ventral BA 6 in

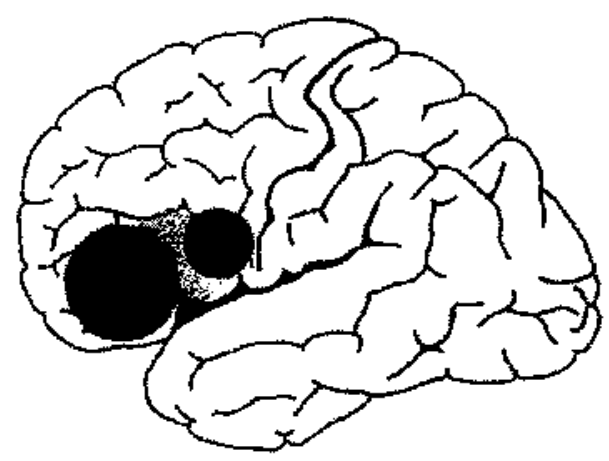

Figure 10. The tmiftation gradtent in lef inferiar frontal cortex. Activations and their distribution are shown, related to semantic (grey), syntaitic (hight grey) and phonological (dark grey) processing. Areas are based on the theta-andlysis in Bookbitiner (2002). The centers represent the mean coordinates of the local maxima, the radit represent the standard deviations of the distance between the local maxima and their means. 
phonological unification (see Figure 10).

\section{Six principles of the processing architecture}

In analogy to other domains of cognitive neuroscience, for language comprehension I have made the distinction between memory retrieval and unification or binding. I have discussed features of the processing architecture for syntactic and semantic unification. Evidence from neuroimaging studies seems to support the distinction between brain areas recruited for mernory retrieval and brain areas crucial for unification. Based on the evidence discussed in the preceding sections I propose the following six general architectural principles for comprehension beyond the single word level:

(i) The brain honours the distinction between syntactic and semantic unification. However, both involve contributions from the left prefrontal cortex (in and around Broca's area), as the workspace where unification operations take place. It is very well possible that this area is not language-specific, but subserves other functions as well (e.g. binding in music, see Patel, 2003). Left prefrontal cortex is suggested to maintain the activation state of representational structures retrieved from memory (the mental lexicon), and to provide the necessary neuroanatomical space for unification operations.

(ii) Immediacy is the general processing principle of unification. Semantic unification does not wait until relevant syntactic information (such as word class information) is available, but starts immediately with what it derives on the basis of the bottom-up input and the left context. The corollary of immediacy is incrementality: Output representations are built up from left to right in close temporal contiguity to the input signal.

(iii) There does not seem to be a separate stage during which word meaning is exclusively integrated at the sentence-level. Incremental interpretation is for the most part done by an immediate mapping onto a discourse model (Clark, 1996).

(iv) In parsing lexically specified structures enter the unification space. Lexical 
information (e.g. animacy), discourse information, and, based on recent data, other-modality inputs (e.g. visual world, gesture) immediately influence the competition between alternative unification options, and can change the unification links. However, in the absence of competing unification sites, as signment of structure is not influenced by non-syntactic information types.

(v) There is no evidence for a privileged position of syntax and/or a processing priority for syntax, as assumed in syntax-first models. The different processing levels (phonological, syntactic, semantic/pragmatic) operate in parallel, and, to some degree independent. Where necessary, cross-talk takes place, which is again characterized by the immediacy principle. That is, cross-talk takes place on a more or less moment-to-moment basis.

(vi) Within certain limitations, the language comprehension system can adapt the weight of evidence in the light of system-internal or system-external noise. The degrees of freedom in language comprehension are much greater than in language production.

\section{References}

Ajnsworth-Darnell, K., Shulman, H., \& Boland, J. (1998). Dissociating brain responses to syrntactic and sernantic anomalies: Evidence from event-related potentials. Journal of Memory and Language, 38, 112-130.

Aleman, A., Formisano, E., Koppenhagen, H., Hagoort, P., De Haan, E. H. F., \&. Kahn, R. S. (2005). The functional neuroanatomy of metrical stress evatuation of perceived and imagined spoken words. Cerebral Cortcx, 15, 221-228.

Allport, D. A. (1985). Distributed memor man \& R. Epstein (Eds.), Current perspectives in dysphasia 32-60. Edirburgh: Churchill Livingstone.

Altmann. G. T. M., \& Steedman. M. (1988). Interaction with context during human sententet processing. Cognition, 30, 191-238.

Boland, J. E., \& Cutler, A. (1996). Interaction with autonomy: Multiple cutput models and the inadequacy of the great divide. Cognition, $58,309-320$.

Bookheimer, S. (2002). Functional MRI of Language: New apFroaches to understanding the

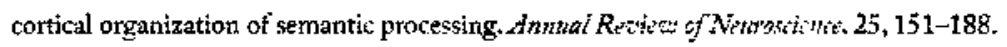

Botrinick, A. B., Cohen, J. D.. \& Carter, C. S. (2004). Conflict monitoring and anterior cingu- 
late cortex: an update. Trends in Cognitigte Sciences, 8, 539-546.

Bresnan, J. W. (2001). Lexical-functional syrtax. Oxford: Blackweil.

Brown, C., \& Hagoort, P. (1993). The processing nature of the N400: Evidence from masked priming. Joumal of Cognitive Neurascience, 5, 34-44.

Bush, G., Luu, P., \& Posner, M. I. (2000). Cognitive and emotional influences in anferior cingulate cortex. Trends in Cognitive Sciences, 4, 215-222.

Caplan, D., Hildebrandt, N., \& Makris, N. (1996). Location of lesions in stroke patients with deftcits in syntactic processing in sentence comprehension. Brain, 119, 933-949.

Chomskw, N. (1995). The minimalist Program. Cambridge (MA): MIT Press.

Clark, H. H. (1996). Using language. Cambridge: Cambridge University Press.

Coulson, S., King, J. W., \& Kutas, M. (1998). Expect the unexpected: Event-related brain response to morphosyntactic violations. Language and Cognitive Processes, 13, 21--58.

Cutler, A., \& Clifton, C. E. (1999). Comprehending spoken language: A blueprint of the listener. In C. M. Brown \& P. Hagoort (Eds.), The netrocognition of language (123-166). Oxford: Oxford University Press.

Damasio, H., Grabowski, T. J., Tranel, D., Hichwa, R. D., \& Damasio, A. D. (1996). A neuraj basis for lexical retrieval. Nature, 380, 499-505.

Duncan, J., \& Miller, E. K. (2002). Cognitive focus through adaptive neural coding in the primate prefrontal cortex. In D. T. Stuss \& R. T. Knight (Eds.), Principles of frontal lobe function (278-292). Oxford: Oxford University Press.

Ericsson, K. A.. \& Kintsch, W. (1995). Long-term working memory. Psycbological Retriew, 102, 211-245.

Fodor,J. D. (198.3). The modularity of mind. Cambridge (Mass.): MTT Press.

Frazier, L. (1987). Sentence processing: A tutorial review. In M. Coltheart (Ed.), Attention and Performance XII (pp. 559-585). London, UK: Erlbaum.

Friederici, A. D. (1995). The time course of syntactic activation during language processing: A model based on neuropsychological and neurophysiological data. Brain and Languzge, $50,259-281$.

Friederici, A. D. (2002). Towards a neural basis of auditory sentence processing. Trends in Cag nitive Sciences, 6, 78-84.

Friederici, A. D., Hahne, A., \& Mecklinger, A. (1996). Temporal structure of syntactic parsing: Early and tate exent-related brain potential effects. Joutnal of Experimental Psychology: Learning, Memory, and Cognition, 22, 1219-1248.

Friederici, A. D., Pfeifer, E., \& Hahne, A. (1993). Event-related brain potentials during natural 
speech processing: Effects of semantic, morphological and syntactic violations. Cognititoz Brain Research, 1, 183-192.

Gibson, E. (1998), Lingustic comlexity: locality of syntactic dependencics. (Xention. $68.1-\bar{t}$.

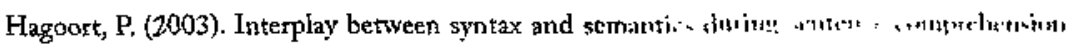
ERP effects of combining syntactic and semaul:, . $i, \ldots$. science, 15, 883-899.

Hagoort, P., \& Brown, C.M. (1994), Brain recentw.

In C. Clifton Jr, L. Frazier \& K. R., a. 81). Hilisdale, NJ: Lawrence Erlbaum,

Hagoort, P., \& Brown, C. M. (2000). ERP eliti:

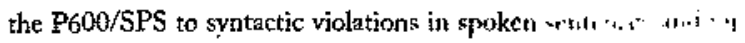
tation. Neturopsychologia, 38, 1531-1549.

Hagoort, P., Brown, C. M., \& Groothusen, J. (1993). The Syntactic Positive Shift (SPS) as an ERP measure of syntactic processing. Language and Cognitioi Processe. 8, 439-483.

Hagoort, P., Brown, C., \&. Osterhout. L. (1999). The neurocogsition of syntactic processing. In C. M. Brown \& P. Hagoort (Eds.), Neurocognition of Language (273-317). Oxford: Oxford University Press.

Hagoort, P., Hald, L., Bastiaansen, M., \& Petersson, K. M. (2004). Integration of Word Meaning and World Knowledge in Language Comprehension. Stiznce, 304, 438-441.

Hagoort, P., Wassenaar, M. \& Brown, C. M. (2003). Syntax-related ERP-effects in Dutch. Cognifice Brain Resarib, 16, 38-50.

Hahne, A., \& Jescheniak, \}. D. (2001). What's left if the Jabberwock gets the semantics? An ERP investigation into semantic and syntactic processes during auditory sentence comprehension. Cognitize Brain Rextat b. 11, 199-212.

Harbusch, K., \& Kempen, G. (2002). A quantiative model of word order ind morement in Eng7ish, Dutch and German omplement contrations. Paper presented at the 19th international conference or computational linguistics (COLING-2002), San Francisco.

Indefrey, P. (2003). Hirnaktivienungen bei sụntaktischer Sprachrerarbeirung: eine Mvleta-Analyse. In G.Rickheit \& H. M. Mueller (Eds.), Neurokgnition in der Spratbe. Tübingen: Stauffenburg Verlag.

Indefrey, P., \& Cutler, A. (2005). Prelexical and lexical processing in listening. In M. D. Gazzaniga (Ed.), Tbe cognitize neurostiences (3rd ed.). Cambridge, MA: MIT Press.

Indefrex; P., \& Levelt, W. J. M. (2000). The nearal correlates of language production. In M. \$. Gazzaniga (Ed.), Tbe nezi rognitize murostientes (2nd ed., 8-5-865). Cambridge, MA: 


\section{MIT Press.}

Jackendoff, $R$. (1999). The representational structures of the language factlty and their interactions. In C. M. Brown \& P. Hagoort (Eds.), The nearocognition of language (37-79). Oxford UK: Oxford University Press.

Jackendoff, R. (2002). Foundations of language: Brain, meaning, grammar, evolution. Oxford, UK: Oxford University Press.

Joshi, A. K., \& Schabes, Y. (1997). Treeadjoining grammars, In A. Salomera \& G. Rosenberg (Eds.), Handbook of formal languages and atutomata (Vol. 3, 69-124). Heidelberg: Springer-Verlag.

Kaan, E., Harris, A., Gibson, E., \& Holcomb, P. (2000). The P600 as an index of syntactic integration difficulty. Language and Cagnitive Processes, 15, 159-201.

Kaan, E., \& Swaab, T. Y. (2003a). Electrophysiological evidence for serial sentence processing: a comparison between non-preferred and ungrammatical continuations. Cognitive Brain Research, 17, 621-635.

Kaan, E., \& Swasb, T. Y. (2003b). Repair, revision and complexity in syntactic analysis: An electrophysiological differentiation. Journal of Cognitive Neurostience, 15, 98-110.

King, J. W., \& Kutas, M. (1995). Who did what and when? Using word- and clause-level ERPs to thonitor working memory usage in reading. Journal of Cognitiqe Neuroscience, 7, 376395.

Kintsch, W. (1998). Comprebension: A paradigm for cognition. Cambridge: Cambridge University Press.

Kluender, R., \& Kutas, M. (1993). Subjacency as a processing phenomenon. Langtaage and Cognifive Processes, 8, 573-633.

Kuperberg, G. R., Sitnikova, T., Caplan, D., \& Holcomb, P. J. (2003). Ełectrophysiological distinctions in processing conceptual relationships within simple sentences. Cognitioe Brain Research, 17, 117-129.

Kutas, M., \& Hillyard, S. A. (1980), Reading sencelese sentences: Brain potentials reftect semantic anomaly. Science, 207, 203-205.

Kutas, M., \& Van Petten, C. K. (1994), Psycholinguistics electrified: Event-related brain potential investigations. In M. A. Gernsbacher (Ed.), Handbook of psycholinguistics (83-143). San Diego: Academic Press.

L.evelt, W. J. M. (1999). Producing spoken language: A blueprint of the speaker. In C. M. Brown \& P. Hagoort (Eds.), The neuracognition of language (83-122). Oxford: Oxford University Press. 
MacDonald, M. C., Pearlmutter, N. J., \& Seidenberg, M. S. (1994). Lexical nature of syntactic ambiguity resolution. Psychological Review, 101, 676-703.

MacLeod, C. M., \& MacDonald, P. A. (2000). Interdimensional interference in the Stroop effect; uncovering the cognitive and neural anatomy of attention. Trends in Cognitive Sciences, 4, 383-391.

Marslen-Witson, W. (1989). Access and integzation: Projecting sound onto meaning. In W. Marslen-Wilson (Ed.), Lexical representation and process (3-24). Cambridge, MA: The MIT Press.

Marsien-Wilson, W., \& Tvier, L. K. (1980). The temporal structure of spoken language understanding, Cognition, 8, 1-71.

McKinnon, R., \& Osterhout, L. (1996). Constraints on movemest phenomena in sentence processing: Evidence from event-related brain potentials. Language ant Cognitive processes, $11,495-523$.

Mesulam, M.-M. (2002). The human frontal lobes: Transcending the cefault mode through contingent encoding. In D. T. Stuss \& R. T. Knight (Eds.), Principles of frontal lobe function (8-31). Oxford: Oxford University Press.

Miller, E. K. (2000). The prefrontal cortex and cognitive control. Nature Retive Neuroscience, 1. $59-65$.

Münte, T. F., \& Heinze, H. J. (1994). ERP negativities during syntactic processing of written words. In H. J. Heinze. T. F. Münte \& H. R. Mangun (Eds.), Cognitizz etectropbysiology (211-238). Boston, MA: Birkhauser.

Münte, T. F., Heinze, H. J., \& Mangun, G. R. (1993). Dissociation of brain activity related to syntactic and semantic aspects of language. Journal of Cognitize Netrosizence, 5, 335-344.

Münte, T. F., Matzke, M., \& Johannes, S. (1997). Brain activity associated with syntactic incongruities in words and pseudo-words. Journal of Cognitice Naurossience, 9,300-311.

Neville, H., Nicol, J. L., Barss, A., Forster, K. I., \& Garrett, MI. F. (1991). Syntactically based sentence processing classes: Evidence from event-related brain potentials, Journul of ${ }^{\prime} \mathrm{Cog}$ nitive Neuroscience, 3, 151-165.

O'Seaghdha, P. G. O. (1997). Conjoint and dissaciable effects of syntactic and semontic context. Journal of Experimental Psybology, 23, 807-828.

Osterhout, L., Bersick, M., \& MicKinnon, R. (1997). Brain porentials elicited by words: Word length and frequency predict the latency of an early negativity. Biologizal Psycholggi, 16 , 143-168.

Osterhout, L., \& Hagoort, P. (1999). A superticial resemblance doesnit necessarily mean yourre 
part of the family: Counterarguments to Coulson, King, and Kutas (1998) in the P600/ SPS debate. Language and Cognitive Processes, 14, 1-14.

Osterhout, L., \& Holcomb, P. J. (1992), Event-related brain potentials elicited by syntactic anomaly. Journal of Memory and Language, 31, 785-806.

Osterhout, L., \& Holcomb, P. J. (1993). Event-related potentials and syntactic anomaly; evidence of anomaly detection dusing the perception of continuous speech. Langwage and Cognitive Processes, 8, 413-438.

Osterhout, L., \& Holcomb, P. J. (1995). Event-related potentials and language comprehension. In M. D. Rugg \& M. G. H. Coles (Eds.), Electrophysiology of mind (171-215). Oxford, UK: Oxford University Press.

Osterhout, L., Holcomb, P. J., \& Swinney, D. A. (1994). Brain potentials elicited by garden-path sentences: Evidence of the application of verb information during parsing, Journal of Experimental Psychology: Learning, Memory, and Cognition, 20, 786-803.

Osterhout, L., \& Mobley, L. A. (1995). Event-related brain potentials elicited by failure to agree. Journal of Memory and Language, 34, 739-773.

Roelofs, A., \& Hagoort, P. (2002). Control of language use: cognitive modeling the hemodynamics of Stroop task performance. Cognitive Brain Research, 15, 85-97.

Rösler, F., Friederici, A. D., Pütz, P., \& Hahne, A. (1993). Event-related brain potentials while encountering sernantic and syntactic constraint violations. Journal of Cognitive Neuroscience, $5,345-362$.

Saffran, E., \& Sholl, A. (1999). Clues to the functional and neural architecture of word meaning. In C. M. Brown \&. P. Hagoort (Eds.), 7he neurocognition of langtuze (pp. 241-273). Oxford: Oxford University Press.

Scott, S. K., \& Johnsrude, I. S. (2003). The neuroanatomical and functional organization of speech perception. Trends in Neurosciences, 26, 100-107.

Stalnaker, R. C. (1978). Assertion. In P. Cole (Ed.), Syntax and semantics 9: Pragmatics (pp. 315332). New York: Academic Press.

Tanenhaus, M. K., \& Trueswell, C. (1995). Sentence comprehension. In J. L. Mitler \& P. D. Eimas (Eds.), Speech, language, and communication (217-262). San Diego: Acadertic Press.

Thompson-Schill, S. L., D'Esposito, M., \& Kan, E. P. (1999). Effects of repetition and competition on activity in left prefrontal cortex daring word generation. Neuron, 23, 513-522.

Truesweil, J. C., Tanenhaus, M. K., \& Garnsey, S. M. (1994). Semantic influences on parsing: Use of thematic role information in syntactic ambiguity resolation. Journal of Memory and Language, 33, 285-318. 
Trueswell, j. C., Tanenhaus, M. K., \& Kello, C. (1993). Verb-Specific Constraints in Sentence Processing: Separating Effects of Lexical Preference From Garden-Paths. Journal of Experimental Psychology: Learning, .Memory, and Cognition, 19, 528-553.

Tyler, L. K., \& Marslen-Wilson, W. D. (1977). The on-line effects of semantic context on syntactic processing. Journal of Verbul Learning and Verbal Bebavior, 16, 683-692.

Van Berkum, J.J., Brown, C.M., \& Hagoort, P. (19992). Early referential context effects in sentence processing: evidence from event-rełated brain potentials. Jour is of Memory and Language, 41, 147-182.

Van Berkum, J.J., Brown, C.M., \& Hagoort, P. (1999b). When does gender constrain pazsing: Evidence from ERPs. Journal of Pycholinguistic Researth, 28, 555-571.

Van den Brink, D., \& Hagoort, P. (2004). The influence of semantic and syntactic context constraints on lexical selection and integration in spoken-word comprehension as revealed by ERPs. Journal of Cagnitive Neuroscicnce, 16, 1068-1084.

Vosse, T., \& Kempen, G.A.M. (2000). Syntactic stracture assembly in human parsing: a computational model based on competitive inhibition and lexicalist grammat. Cognition, 75 , $105-143$.

Zurif, E.B. (1998). The neurological organization of some aspects of sentence comprehension. Journal of Psvebolinguistic Researth, 27, 181-190. 